\title{
ANALISIS SPASIAL PENGARUH TINGKAT PENGANGGURAN TERHADAP KEMISKINAN DI INDONESIA (Studi Kasus Provinsi Jawa Tengah)
}

\author{
Rita Rahmawati ${ }^{1}$, Diah Safitri ${ }^{2}$, Octafinnanda Ummu Fairuzdhiya ${ }^{3}$ \\ ${ }^{1,2}$ Staf Pengajar Jurusan Statistika UNDIP \\ ${ }^{3}$ Alumnus Jurusan Statistika UNDIP
}

\begin{abstract}
Poverty is still being one of big problems in Indonesia. Any efforts are done to find a solution for this problem. Poverty itself can be caused of the high unemployment that occurs. With a number of unemployment, it will be lower income thus reducing also purchasing power and the ability to meet the needs of life thus causing poverty. This study analyzed the impact of unemployment to the poverty as involving spatial factors, using spatial regression analysis. Used data on poverty and unemployment in each regency in the central java, the analysis shows that based on likelihood ratio test, obtained LR test value 6,038 or p-value 0,014001 which means there is a spatial correlation. By testing model simultaneously nor individually using Breusch-Pagan test and Wald test, it show that both are significant, with $\mathrm{BP}=6,7094 ; \mathrm{df}=1 ; \mathrm{p}$-value $=0,009591$ and Wald statistic $=7,0238$; p-value $=0,0080434$. The results means there are spatial element in the relations between unemployment and poverty in central java so that SEM is more proper used than ordinary linear regression.
\end{abstract}

Keywords: Spatial Error Model (SEM), Spatial Autocorrelation, Spatial Heterogeneity

\section{Pendahuluan}

Data dari Badan Pusat Statistik (BPS) mencatat bahwa terdapat 28,55 juta penduduk Indonesia yang masuk kategori miskin. Penduduk miskin dikategorikan sebagai kalangan masyarakat dengan pengeluaran per kapita per bulan di bawah Garis Kemiskinan $^{[5]}$. Dari situs resmi Kementerian Keuangan ${ }^{[3]}$, Menteri Perencanaan Pembangunan Nasional/Kepala Badan Perencanaan Pembangunan Nasional mengatakan, terdapat 3 hal utama yang ditegaskan melalui Musyawarah Perencanaan Pembangunan Nasional (Musrenbangnas) tahun 2014. Ketiga hal tersebut adalah (1) reformasi yang berjalan perlu diteruskan, (2) percepatan pembangunan ekonomi di segala bidang dan (3) pembangunan yang inklusif. Pemerintah menargetkan pertumbuhan ekonomi 5,5\% sampai $6,3 \%$ pada akhir tahun 2015. Adapun laju inflasi akan ditergetkan terkendali pada kisaran 4,5\%. Menurutnya, pemerintah juga menargetkan penurunan angka kemiskinan dan pengangguran yang signifikan pada akhir 2015, dimana kemiskinan di Indonesia akan turun menjadi 9\% hingga 10\%. Sedangkan angka pengangguran 5,7\% hingga 5,9\%.

Secara umum, pengeluaran seseorang akan sangat dipengaruhi oleh pendapatannya. Dan pendapatan seseorang hanya akan diperoleh dengan baik jika orang tersebut mempunyai pekerjaan. Analogi dengan hal tersebut, banyaknya kemiskinan di suatu wilayah sangat mungkin juga dipengaruhi oleh banyaknya orang yang tidak mempunyai pekerjaan, atau tingkat pengangguran di wilayah tersebut. Sehingga dalam berbagai kesempatan seringkali pembahasan untuk pengentasan kemiskinan juga akan dibarengi dengan penanggulangan pengangguran. Banyaknya orang yang mengganggur akan mempengaruhi jumlah orang miskin (kemiskinan). 
Dalam statistika, pengaruh suatu variabel terhadap variabel lain dapat dibahas dalam analisis regresi. Dengan regresi, akan dihasilkan suatu model persamaan yang dapat digunakan untuk memprediksi variabel dependen jika diketahui variabel independennya. Namun regresi biasa dengan metode OLS (ordinary least square) ini tidak memperhatikan posisi atau lokasi data yang digunakannya. Regresi OLS tidak memperhatikan unsur spasial dalam analisisnya. Hukum pertama tentang geografi yang menjadi salah satu dasar pengembangan analisis spasial dikemukakan oleh Tobler yang menyatakan "everything is related to everything else, but near things are more related than distant things" ${ }^{\text {"[7] }}$. Segala sesuatu saling berhubungan satu dengan yang lainnya, tetapi sesuatu yang lebih dekat akan lebih berpengaruh daripada sesuatu yang lebih jauh. Pada umumnya efek atau pengaruh spasial ini adalah memang hal yang cukup lazim terjadi pada setiap data cross section.

Dari semua pemaparan di atas, tulisan ini membahas tentang analisis spasial untuk melihat pengaruh tingkat pengangguran terhadap kemiskinan dengan regresi spasial. Dengan analisis ini akan lebih diketahui jika memang terdapat juga pengaruh spasial yang tidak dapat diabaikan dalam suatu model regresi, sehingga dalam implementasinya pun penanggulangan kemiskinan dapat dilakukan dengan lebih komprehensif. Secara sederhana, dapat dikatakan bahwa, untuk mengatasi kemiskinan di suatu wilayah tertentu di Indonesia, maka pemerintah pun harus memperhatikan keadaan "tetangga" dari wilayah tersebut. Tujuan penelitian ini adalah untuk melihat pengaruh pengangguran terhadap tingkat kemiskinan di Indonesia. Dengan data yang digunakan adalah data tiap provinsi di Indonesia, maka akan diketahui bilamana pengangguran di suatu provinsi dapat juga mempengaruhi kemiskinan provinsi "tetangga"nya (secara geografis berdekatan dengan provinsi tersebut).

\section{Tinjauan Pustaka}

\subsection{Analisis Data Spasial}

Data spasial adalah data yang berkaitan dengan lokasi, berdasarkan geografi yang terdiri dari lintang-bujur dan wilayah. Analisis data spasial tidak dapat dilakukan secara global, artinya setiap lokasi mempunyai karakteristik sendiri. Sebagian besar pendekatan analisisnya merupakan eksplorasi data yang disajikan dalam bentuk peta tematik. Peta tematik juga disebut sebagai peta statistik atau peta tujuan khusus, menghasilkan gambaran penggunaan ruangan pada tempat tertentu sesuai dengan tema yang diinginkan. Berbeda dengan peta rujukan yang memperlihatkan pengkhususan geografi (hutan, jalan, perbatasan administratif), peta-peta tematik lebih menekankan variasi penggunaan ruangan daripada sebuah jumlah atau lebih dari distribusi geografis. Distribusi geografis bisa berupa fenomena fisikal seperti iklim atau ciri-ciri khas manusia seperti kepadatan penduduk atau permasalahan kesehatan ${ }^{[6]}$. Konsep Analisis Data Spasial terdiri dari Spatial Dependence, Spatial Heterogeneity, Spatial Autocorrelation.

\subsection{Model Regresi Spasial} berikut

Menurut LeSage (1999) ${ }^{[4]}$, secara umum model regresi spasial adalah sebagai

$$
\begin{aligned}
& \boldsymbol{y}=\rho \boldsymbol{W}_{\mathbf{1}} \boldsymbol{y}+\boldsymbol{X} \boldsymbol{\beta}+\boldsymbol{u} \\
& \boldsymbol{u}=\lambda \boldsymbol{W}_{\mathbf{2}} \boldsymbol{u}+\boldsymbol{\varepsilon} \\
& \boldsymbol{\varepsilon} \sim N\left(0, \sigma^{2} \boldsymbol{I}\right)
\end{aligned}
$$

dengan $\quad \boldsymbol{y}$ : vektor variabel respon berukuran $n \times 1$

$\boldsymbol{X}$ : matriks variabel prediktor berukuran $n \times(k+1)$

$\boldsymbol{\beta}$ : vektor parameter koefisien regresi berukuran $(k+1) \times 1$

$\rho$ : parameter koefisien spasial lag variabel prediktor 
$\lambda$ : parameter koefisien spasial pada galat

$\boldsymbol{u}$ : vektor galat persamaan (1) berukuran $n \times 1$

$\boldsymbol{\varepsilon}$ : vektor galat persamaan (2) berukuran $n \times 1$

$\boldsymbol{W}_{1}, \boldsymbol{W}_{2}$ : matriks pembobot berukuran $n \times n$

I : matriks identitas berukuran $n \times n$

Berdasarkan model umum di atas, dapat diperoleh beberapa model berikut:

1. Jika $W_{2}=0$ maka akan menjadi Spatial Autoregressive Model (SAR). Model ini menunjukkan adanya efek spasial pada variabel respon. Sehingga persamaannya menjadi

$\boldsymbol{y}=\rho \boldsymbol{W}_{\mathbf{1}} \boldsymbol{y}+\boldsymbol{X} \boldsymbol{\beta}+\boldsymbol{u}$

$\boldsymbol{\varepsilon} \sim N\left(\mathbf{0}, \sigma^{2} \boldsymbol{I}\right)$

2. Jika $W_{1}=0$ maka akan menjadi Spatial Error Model (SEM) atau Model Galat

Spasial. Model Galat Spasial adalah model spasial yang menunjukkan adanya efek spasial dalam galat. Sehingga diperoleh persamaan seperti berikut

$\boldsymbol{y}=\boldsymbol{X} \boldsymbol{\beta}+\lambda \boldsymbol{W u}+\boldsymbol{\varepsilon}$

$\boldsymbol{\varepsilon} \sim N\left(\mathbf{0}, \sigma^{2} \boldsymbol{I}\right)$

3. Jika terdapat efek spasial pada variabel respon dan variabel prediktor disebut Spatial Durbin Model. Sehingga model persamaan seperti berikut

$\boldsymbol{y}=\rho \boldsymbol{W}_{1} \boldsymbol{y}+\boldsymbol{X} \boldsymbol{\beta}_{1}+\boldsymbol{W}_{\mathbf{1}} \boldsymbol{X} \boldsymbol{\beta}_{\mathbf{2}}+\boldsymbol{\varepsilon}$

$\boldsymbol{\varepsilon} \sim N\left(\mathbf{0}, \sigma^{2} \boldsymbol{I}\right)$

\subsection{Spatial Error Model (SEM)}

Berdasarkan persamaan SEM atau Model Galat Spasial di atas, persamaan tersebut dapat dijabarkan seperti berikut ini

$$
\begin{aligned}
& \boldsymbol{y}=\boldsymbol{X} \boldsymbol{\beta}+\boldsymbol{u}, \\
& \boldsymbol{u}=\lambda \boldsymbol{W} \boldsymbol{u}+\boldsymbol{\varepsilon} \\
& \boldsymbol{\varepsilon} \sim N\left(\mathbf{0}, \sigma^{2} \boldsymbol{I}\right)
\end{aligned}
$$

\section{Estimasi Parameter}

Estimasi parameter pada model galat spasial diperoleh dengan metode Maximum Likelihood Estimator $^{[1]}$. Fungsi kepadatan peluang dari $\varepsilon_{i}$

$$
f\left(\varepsilon_{i}\right)=\frac{1}{\sigma \sqrt{2 \pi}} \exp \left(-\frac{\varepsilon_{i}^{2}}{2 \sigma^{2}}\right)
$$

Fungsi kepadatan peluang bersama dari n peubah acak $\varepsilon_{1}, \varepsilon_{2}, \ldots, \varepsilon_{n}$

$$
\begin{aligned}
f(\varepsilon) & =f\left(\varepsilon_{1}\right) \cdot f\left(\varepsilon_{2}\right) \ldots f\left(\varepsilon_{n}\right) \\
& =\left[\left(\frac{1}{\sigma \sqrt{2 \pi}} \exp \left(-\frac{\varepsilon_{1}^{2}}{2 \sigma^{2}}\right)\right)\left(\frac{1}{\sigma \sqrt{2 \pi}} \exp \left(-\frac{\varepsilon_{2}^{2}}{2 \sigma^{2}}\right)\right) \ldots\left(\frac{1}{\sigma \sqrt{2 \pi}} \exp \left(-\frac{\varepsilon_{n}^{2}}{2 \sigma^{2}}\right)\right)\right] \\
& =\frac{1}{(2 \pi)^{n / 2} \sigma^{n}} \exp \left[-\frac{\sum_{i=1}^{n} \varepsilon_{i}^{2}}{2 \sigma^{2}}\right] \\
& =\frac{1}{(2 \pi)^{n / 2} \sigma^{n}} \exp \left[-\frac{\varepsilon^{\prime} \varepsilon}{2 \sigma^{2}}\right]
\end{aligned}
$$

Berdasarkan Persamaan (3) diperoleh

$$
\boldsymbol{u}=\boldsymbol{y}-\boldsymbol{X} \boldsymbol{\beta} \text { dan } \boldsymbol{\varepsilon}=(\boldsymbol{I}-\lambda \boldsymbol{W u}) \boldsymbol{u}
$$

Sehingga $\boldsymbol{\varepsilon}=(\boldsymbol{I}-\lambda \boldsymbol{W} \boldsymbol{u})(\boldsymbol{y}-\boldsymbol{X} \boldsymbol{\beta})$

Fungsi kepadatan peluang bersama dari n peubah tak bebas $\mathbf{y}$

$$
\begin{aligned}
f(\boldsymbol{y}) & =f(\boldsymbol{\varepsilon})|\boldsymbol{J}| \\
& =\frac{1}{(2 \pi)^{n / 2} \sigma^{n}} \exp \left[-\frac{\boldsymbol{\varepsilon}^{\prime} \boldsymbol{\varepsilon}}{2 \sigma^{2}}\right]\left|\frac{d \boldsymbol{\varepsilon}}{d \boldsymbol{y}}\right| \\
& =\frac{1}{(2 \pi)^{n / 2} \sigma^{n}} \exp \left[\frac{[(\boldsymbol{I}-\lambda \boldsymbol{W u})(\boldsymbol{y}-\boldsymbol{X} \boldsymbol{\beta})]^{\prime}(\boldsymbol{I}-\lambda \boldsymbol{W u})(\boldsymbol{y}-\boldsymbol{X} \boldsymbol{\beta})}{2 \sigma^{2}}\right]|\boldsymbol{I}-\lambda \boldsymbol{W}|
\end{aligned}
$$


Fungsi peluang peubah tak bebas $\mathbf{y}$

$$
\begin{aligned}
& L\left(\beta, \lambda, \sigma^{2} ; y\right)=f\left(y ; \beta, \lambda, \sigma^{2}\right) \\
& \quad=\frac{|\boldsymbol{I}-\lambda \boldsymbol{W}|}{(2 \pi)^{n / 2} \sigma^{n}} \exp \left[\frac{[(\boldsymbol{I}-\lambda \boldsymbol{W} \boldsymbol{u})(\boldsymbol{y}-\boldsymbol{X} \boldsymbol{\beta})]^{\prime}(\boldsymbol{I}-\lambda \boldsymbol{W} \boldsymbol{u})(\boldsymbol{y}-\boldsymbol{X} \boldsymbol{\beta})}{2 \sigma^{2}}\right]
\end{aligned}
$$

Pendugaan parameter diperoleh dengan memaksimalkan logaritma dari fungsi peluang.

$$
\begin{aligned}
\mathrm{L} & =\ln \left(L\left(\beta, \lambda, \sigma^{2} ; y\right)\right) \\
& =\ln \left(\frac{|\boldsymbol{I}-\lambda \boldsymbol{W}|}{(2 \pi)^{n / 2} \sigma^{n}} \exp \left[\frac{[(\boldsymbol{I}-\lambda \boldsymbol{W u})(\boldsymbol{y}-\boldsymbol{X} \boldsymbol{\beta})]^{\prime}(\boldsymbol{I}-\lambda \boldsymbol{W u})(\boldsymbol{y}-\boldsymbol{X} \boldsymbol{\beta})}{2 \sigma^{2}}\right]\right)
\end{aligned}
$$

Sehingga diperoleh fungsi log-likelihood sebagai berikut

$$
\mathrm{L}=-\frac{n}{2} \ln (2 \pi)-\frac{\mathrm{n}}{2} \ln \left(\sigma^{2}\right)+\ln |\boldsymbol{I}-\lambda \boldsymbol{W}|-\frac{(\boldsymbol{y}-\boldsymbol{X} \boldsymbol{\beta})^{\prime}(\boldsymbol{I}-\lambda \boldsymbol{W})^{\prime}(\boldsymbol{I}-\lambda \boldsymbol{W})(\boldsymbol{y}-\boldsymbol{X} \boldsymbol{\beta})}{2 \sigma^{2}}
$$

Dengan memaksimumkan fungsi log-likelihood diperoleh pendugaan parameter $\widehat{\boldsymbol{\beta}}$ dan $\hat{\sigma}^{2}$ Penduga untuk $\boldsymbol{\beta}$ adalah

Penduga untuk $\sigma^{2}$ adalah

$$
\widehat{\boldsymbol{\beta}}=\left(\boldsymbol{X}^{\prime}(\boldsymbol{I}-\lambda \boldsymbol{W})^{\prime}(\boldsymbol{I}-\lambda \boldsymbol{W}) \boldsymbol{X}\right)^{-1} \boldsymbol{X}^{\prime}(\boldsymbol{I}-\lambda \boldsymbol{W})^{\prime}(\boldsymbol{I}-\lambda \boldsymbol{W}) \boldsymbol{y}
$$

$$
\hat{\sigma}^{2}=\frac{(\boldsymbol{I}-\lambda \boldsymbol{W})^{\prime}(\boldsymbol{y}-\boldsymbol{X} \widehat{\boldsymbol{\beta}})^{\prime}(\boldsymbol{I}-\lambda \boldsymbol{W})(\boldsymbol{y}-\boldsymbol{X} \widehat{\boldsymbol{\beta}})}{n}
$$

Pengujian signifikansi parameter pada pemodelan spasial dalam penelitian ini menggunakan uji Wald ${ }^{[1]}$.

Hipotesis :

$$
\begin{aligned}
& H_{0}: \theta_{p}=0 \\
& H_{1}: \theta_{p} \neq 0
\end{aligned}
$$

Statistik uji Wald $=\frac{\widehat{\theta}_{p}^{2}}{\operatorname{var}\left(\widehat{\theta}_{p}\right)}$

dengan $\quad \hat{\theta}_{p}^{2} \quad$ : estimasi parameter $\beta$

$\operatorname{var}\left(\hat{\theta}_{p}\right):$ varian estimator parameter $\beta$

Pengambilan keputusan $H_{0}$ ditolak jika nilai statistik uji Wald $>\chi_{\alpha, 1}^{2}$

\subsection{Uji Efek Spasial}

Untuk mengetahui adanya efek spasial yaitu spatial dependence dan spatial heterogenity pada data, digunakan beberapa metode pengujian. Pengujian dependensi spasial menggunakan Likelihood Ratio (LR), sedangkan untuk pengujian heterogenitas spasial menggunakan metode Uji Breusch-Pagan ${ }^{[1]}$.

1. Uji Dependensi Spasial (Spatial Dependence)

Pengujian hipotesisnya adalah

$$
\begin{aligned}
& H_{0}: \lambda=0 \text { (tidak ada korelasi spasial) } \\
& H_{1}: \lambda \neq 0 \text { (ada korelasi spasial) }
\end{aligned}
$$

Fungsi likelihood untuk model galat spasial adalah

$$
\mathrm{L}=-\frac{n}{2} \ln (\pi)-\frac{\mathrm{n}}{2} \ln \left(\sigma^{2}\right)+\ln |\boldsymbol{I}-\lambda \boldsymbol{W}|-\frac{(\boldsymbol{y}-\boldsymbol{X} \boldsymbol{\beta})^{\prime}(\boldsymbol{I}-\lambda \boldsymbol{W})^{\prime}(\boldsymbol{I}-\lambda \boldsymbol{W})(\boldsymbol{y}-\boldsymbol{X} \boldsymbol{\beta})}{2 \sigma^{2}}
$$

Fungsi likelihood pada $\mathrm{H}_{0}$ adalah

$$
\mathrm{L}_{0}=-\frac{n}{2} \ln (\pi)-\frac{\mathrm{n}}{2} \ln \left(\sigma^{2}\right)-\frac{(\boldsymbol{y}-\boldsymbol{X} \boldsymbol{\beta})^{\prime}(\boldsymbol{y}-\boldsymbol{X} \boldsymbol{\beta})}{2 \sigma^{2}}
$$

Statistik Likelihood Ratio Test (LRT) merupakan selisih dari kedua fungsi likelihood di atas, sehingga

$$
L R T=2\left(L-L_{0}\right)
$$




$$
\begin{aligned}
& L R T=2\left\{-\frac{n}{2} \ln (\pi)-\frac{\mathrm{n}}{2} \ln \left(\sigma^{2}\right)+\ln |\boldsymbol{I}-\lambda \boldsymbol{W}|-\frac{(\boldsymbol{y}-\boldsymbol{X} \boldsymbol{\beta})^{\prime}(\boldsymbol{I}-\lambda \boldsymbol{W})^{\prime}(\boldsymbol{I}-\lambda \boldsymbol{W})(\boldsymbol{y}-\boldsymbol{X} \boldsymbol{\beta})}{2 \sigma_{1}^{2}}-\right. \\
& \left.\left(-\frac{n}{2} \ln (\pi)-\frac{\mathrm{n}}{2} \ln \left(\sigma^{2}\right)-\frac{(\boldsymbol{y}-\boldsymbol{X} \boldsymbol{\beta})^{\prime}(\boldsymbol{y}-\boldsymbol{X} \boldsymbol{\beta})}{2 \sigma_{0}^{2}}\right)\right\} \\
& L R T=n\left[\ln \left(\sigma_{0}^{2}\right)-\ln \left(\sigma_{1}^{2}\right)\right]+2 \ln |\boldsymbol{I}-\lambda \boldsymbol{W}| \\
& \sigma_{1}^{2} \text { : varian dari galat untuk model spasial }
\end{aligned}
$$

Untuk menguji signifikansi dari koefisien korelasi spasial $(\hat{\lambda})$ digunakan LRT.

Pengambilan keputusan $H_{0}$ ditolak jika nilai LRT $>\chi_{\alpha, 1}^{2}$.

2. Uji Heterogenitas Spasial (Spatial Heterogenity)

Heterogenitas spasial dapat diuji dengan menggunakan uji Breusch-Pagan ${ }^{[1]}$ yang mempunyai hipotesis sebagai berikut

$H_{0}$ : Terdapat homogenitas spasial

$H_{1}$ : Terdapat heterogenitas spasial

Nilai Uji Breusch-Pagan

$$
B P=\frac{1}{2} \mathbf{f}^{\mathbf{T}} \mathbf{Z}\left(\mathbf{Z}^{\mathrm{T}} \mathbf{Z}\right)^{-\mathbf{1}} \mathbf{Z}^{\mathbf{T}} \mathbf{f} \sim \chi_{p}^{2}
$$

dengan elemen vektor $\mathbf{f}$

$$
f_{i}=\left(\frac{e_{i}^{2}}{\sigma^{2}}-1\right)
$$

dimana $e_{i}^{2}$ : galat untuk observasi ke-i

$\mathbf{Z}$ : matriks berukuran $n \times(p+1)$ yang berisi vektor yang sudah distandarkan (z) untuk setiap observasi

Pengambilan keputusan $H_{0}$ ditolak jika BP $>\chi_{\alpha, 1}^{2}$.

\subsection{Matriks Pembobot Spasial}

LeSage (1999) menjelaskan ada beberapa metode yang dapat digunakan dalam menentukan matriks pembobot spasial, salah satunya adalah metode Queen Contiguity yang akan digunakan dalam penelitian ini. Metode Queen Contiguity mendefinisikan bahwa $\mathrm{W}_{\mathrm{ij}}=1$ jika lokasi bersinggungan sisi atau sudut dengan lokasi lainnya, sedangkan $\mathrm{W}_{\mathrm{ij}}=0$ jika tidak bersinggungan. Sebagai ilustrasi, Gambar 1 merupakan contoh pembentukan matriks pembobot spasial Queen dengan lima entitas atau area sebagai subjek pengamatan.

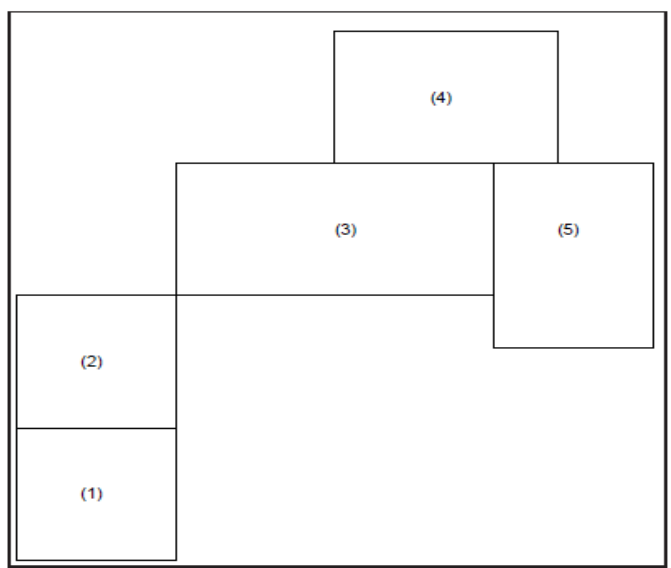

Gambar 1. Ilustrasi Pembobot Spasial 
Matriks pembobot yang terbentuk untuk wilayah pada Gambar 1 adalah

$$
\left[\begin{array}{lllll}
0 & 1 & 0 & 0 & 0 \\
1 & 0 & 1 & 0 & 0 \\
0 & 1 & 0 & 1 & 1 \\
0 & 0 & 1 & 0 & 1 \\
0 & 0 & 1 & 1 & 0
\end{array}\right]
$$

\section{Metode Penelitian}

Permasalahan utama yang ingin diselesaikan dalam penelitian ini adalah membuktikan dan menunjukkan adanya kemungkinan masuknya unsur spasial dalam memodelkan kemiskinan sebagai fungsi dari pengangguran. Dalam hal ini digunakan salah satu jenis regresi spasial yaitu spasial error model (SEM), dengan prosedur sebagai berikut:

1. Menentukan matriks pembobot spasial dengan metode Queen Contiguity

2. Melakukan uji dependensi spasial dan heterogenitas spasial

3. Mencari estimasi parameter SEM

4. Melakukan pengujian signifikansi parameter model

5. Membuat kesimpulan

Data yang digunakan diperoleh dari data publikasi BPS pada Jawa Tengah dalam Angka ${ }^{[2]}$.

\section{Hasil Dan Pembahasan}

\subsection{Deskripsi Data Penelitian}

Data yang digunakan dalam penelitian ini merupakan data sekunder yang diperoleh dari BPS, yaitu data jumlah pengangguran $(\mathrm{P})$ dan jumlah penduduk miskin $(\mathrm{M})$, yang masing-masing dalam satuan ribu jiwa, dari 35 Kabupaten/kota di Jawa Tengah, yaitu:

$\begin{array}{llllll}1 & \text { Kab. Wonosobo } & 13 & \text { Kab. Pati } & 25 & \text { Kab. Karanganyar } \\ 2 & \text { Kab. Wonogiri } & 14 & \text { Kab. Magelang } & 26 & \text { Kab. Jepara } \\ 3 & \text { Kab. Temanggung } & 15 & \text { Kab. Kudus } & 27 & \text { Kab. Grobogan } \\ 4 & \text { Kab. Tegal } & 16 & \text { Kota Tegal } & 28 & \text { Kab. Demak } \\ 5 & \text { Kab. Sukoharjo } & 17 & \text { Kota Surakarta } & 29 & \text { Kab. Cilacap } \\ 6 & \text { Kab. Sragen } & 18 & \text { Kota Semarang } & 30 & \text { Kab. Brebes } \\ 7 & \text { Kab. Semarang } & 19 & \text { Kota Salatiga } & 31 & \text { Kab. Boyolali } \\ 8 & \text { Kab. Rembang } & 20 & \text { Kota Pekalongan } & 32 & \text { Kab. Blora } \\ 9 & \text { Kab. Purworejo } & 21 & \text { Kota Magelang } & 33 & \text { Kab. Batang } \\ 10 & \text { Kab. Purbalingga } & 22 & \text { Kab. Klaten } & 34 & \text { Kab. Banyumas } \\ 11 & \text { Kab. Pemalang } & 23 & \text { Kab. Kendal } & 35 & \text { Kab. Banjarnegara } \\ 12 & \text { Kab. Pekalongan } & 24 & \text { Kab. Kebumen } & & \end{array}$

Berdasarkan data yang diperoleh dari BPS Provinsi Jawa Tengah, pada tahun 2012 jumlah pengangguran terbesar terdapat di Kabupaten Pati yaitu sebesar 78.180 jiwa, dan pengangguran terendah di Kota Magelang, yaitu sebanyak 5.500 jiwa. Sedangkan rata-rata tiap Kab/kota terdapat 27.490 jiwa yang menganggur. Sedangkan jumlah penduduk miskin tertinggi terdapat di Kabupaten Brebes yaitu sebesar 364.900 jiwa, dan jumlah penduduk miskin terendah berada pada daerah yang juga jumlah penganggurannya paling sedikit yaitu Kota Magelang.

Kabupaten Brebes sendiri jumlah penganggurannya adalah terbesar kedua setelah Kabupaten Pati, yaitu sebesar 65.848 jiwa. Sekilas dari deskriptif di atas, memang terdapat 
kecenderungan bahwa semakin banyak pengangguran maka jumlah penduduk miskin di suatu wilayah juga semakin banyak.

\subsection{Uji Efek Spasial}

Uji efek spasial digunakan untuk mengetahui adanya dependensi spasial dan heterogenitas spasial. Likelihood Ratio Test digunakan untuk mendeteksi ketergantungan spasial sedangkan uji heterogenitas spasial dilakukan dengan uji Breusch-Pagan.

1. Dependensi Spasial

Hipotesis untuk pengujian dependensi spasial dengan menggunakan Likelihood Ratio Test adalah sebagai berikut:

$H_{0}$ : Tidak ada korelasi spasial

$H_{l}$ : Ada korelasi spasial

Hasil analisis menunjukkan nilai LR test $=6,038$ dan nilai $p$-value $=0,014001$, kurang dari $\alpha=0,05$ sehingga $H_{0}$ ditolak. Jadi dapat disimpulkan bahwa ada korelasi spasial antar wilayah.

2. Heterogenitas Spasial

Hipotesis untuk pengujian heterogenitas spasial dengan menggunakan Uji BreuschPagan adalah sebagai berikut:

$H_{0}$ : Terdapat homogenitas spasial

$H_{1}$ : Terdapat heterogenitas spasial

Hasilnya, nilai BP test $=6,7094$ dan nilai $p$-value $=0,009591$ kurang dari $\alpha=0,05$ sehingga $H_{0}$ ditolak. Jadi terdapat heterogenitas spasial.

\subsection{Spasial Error Model (Model Galat Spasial)}

Pemodelan Spatial Error Model (SEM) dilakukan dengan menggunakan dua variable, jumlah pengangguran sebagai variabel bebas $(\mathrm{X})$ dan jumlah penduduk miskin sebagai variabel tak bebas (Y). Langkah pertama yang harus dilakukan adalah memasukkan ke dalam database peta Jawa Tengah dengan menggunakan software ArcView GIS 3.2. Untuk menghasilkan matriks pembobot Queen Contiguity, digunakan software GeoDa. Matriks pembobot yang digunakan adalah matriks pembobot yang distandarkan. Dalam melakukan analisis Model Galat Spasial pada penelitian ini digunakan software $\mathrm{R}$ i386 3.0.2 dengan paket spdep. Hasil output $\mathrm{R}$ adalah sebagai berikut:

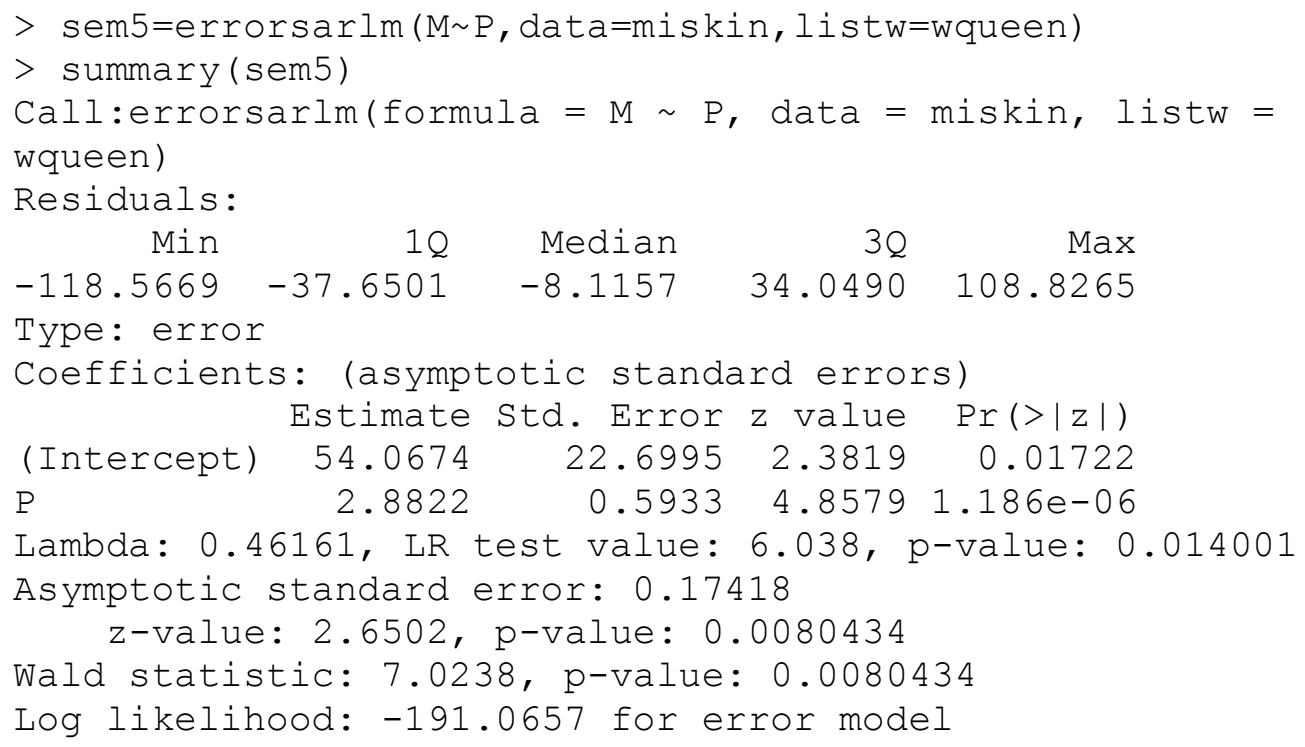




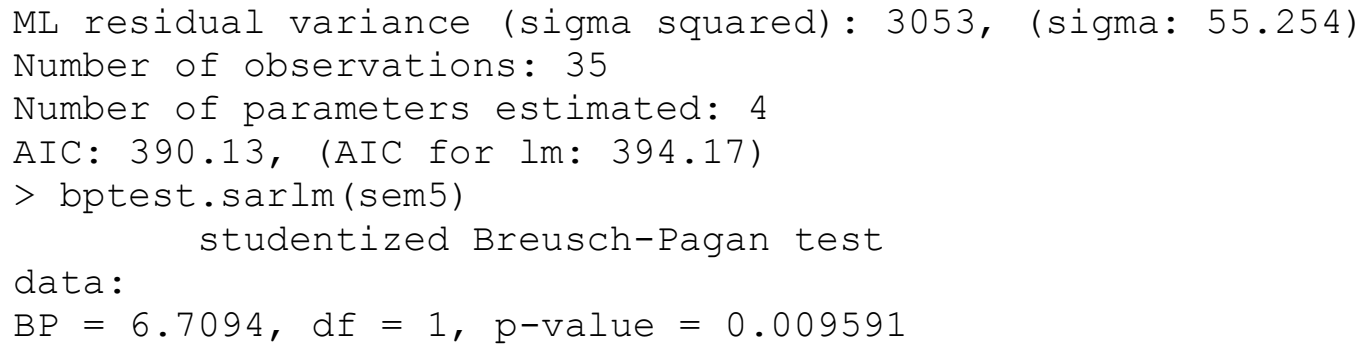

Berdasarkan uji dependensi sebelumnya, disimpulkan bahwa terdapat dependensi spasial, sehingga bisa dilanjutkan ke SEM (Model Galat Spasial). Dari hasil analisis pada output, Model Galat Spasial didapatkan estimasi parameter sebagai berikut

Tabel 1. Estimasi Parameter Model Galat Spasial

\begin{tabular}{cccc}
\hline Parameter & Koefisien & p-value & Kesimpulan \\
\hline (Intercept) & 54,0674 & 0,01722 & Signifikan \\
$\mathrm{P}$ & 2,8822 & $1,186 \mathrm{e}^{-06}$ & Signifikan \\
\hline
\end{tabular}

Berdasarkan hasil tersebut didapatkan Model Galat Spasial sebagai berikut

$$
\begin{aligned}
& \widehat{y_{l}}=54,0674+2,8822 X+\widehat{\boldsymbol{u}_{\boldsymbol{l}}} \\
& \widehat{\boldsymbol{u}_{\boldsymbol{l}}}=0,46161 \sum_{j=1, i \neq j}^{n} W_{i j} \widehat{\boldsymbol{u}_{\boldsymbol{J}}}
\end{aligned}
$$

\section{Kesimpulan}

Berdasarkan hasil analisis dapat disimpulkan bahwa terdapat hubungan signifikan bahwa pengangguran mempengaruhi jumlah penduduk miskin. Terdapat ketergantungan atau dependensi spasial pada model, juga terdapat heterogenitas spasial, sehingga pemodelan regresi spasial yang melibatkan pembobotan data berdasarkan posisi atau lokasi wilayah yang diobservasi lebih tepat digunakan. Dengan spasial error model, regresi yang dihasilkan adalah

$$
\begin{gathered}
\widehat{y_{l}}=54,0674+2,8822 X+\widehat{\boldsymbol{u}_{\boldsymbol{l}}} \\
\widehat{\boldsymbol{u}_{\boldsymbol{l}}}=0,46161 \sum_{j=1, i \neq j}^{n} W_{i j} \widehat{\boldsymbol{u}_{\boldsymbol{J}}}
\end{gathered}
$$

\section{DAFTAR PUSTAKA}

1. Anselin, L., Spatial Econometrics: Methods and Models, Kluwer Academic Publishers, The Netherlands, 1988.

2. BPS, Jawa Tengah dalam Angka 2013, BPS Provinsi Jawa Tengah, 2013.

3. KEMENKEU. 2014. http://www.kemenkeu.go.id/Berita/pemerintah-targetkaninflasi-terkedali-kemiskinan-dan-pengangguran-turun-di-2015 [diakses 21 Juli 2014]

4. LeSage, J. P., The Theory and Practice of Spatial Econometrics, University of Toledo, 1999.

5. Liputan6.com. 2014. http://m.liputan6.com/bisnis/read/790061/jumlah-pendudukmiskin-indonesia-meningkat-jadi-2855-juta-jiwa [diakses 19 Juli 2014]

6. Pfeiffer, D et al., Spatial Analysis in Epidemiologi, Oxford University Press, New York, 2008.

7. Schabenberger O, Gotway CA., Statistical Methods for Spatial Data Analysis, Chapman \& Hall/CRC, 2005. 